\title{
Hybridisation of Peacebuilding at the Local-International Interface: The Bougainville Case
}

\author{
Volker Boege
}

\section{Introduction}

This chapter builds its argument on a relational understanding of hybridity, focusing on hybridisation - of peace, governance, security, sociopolitical order - as an ongoing process of becoming through mixing, reconverting, leaching and blending. The concept of hybridisation tries to capture the fluid, dynamic, emergent and relational quality of the reality it is meant to grasp. ${ }^{1}$ Talking about the process of hybridisation allows us to shift attention from fixed entities to relations. ${ }^{2}$ Let us be reminded that protagonists of the hybridity approach initially introduced the term into the scholarly debate about peacebuilding not least with the aim of overcoming reductive dichotomies, to open space for reflection about enmeshment, permeation, interpenetration, liminality, entanglement, fluidity, slippage, ambiguity, in-betweenness, dynamics and relations, with the shift away from binaries as 'the primary appeal of hybridity and hybridisation'. ${ }^{3}$

1 See Hunt, this volume.

2 This in turn allows us to respond to the critique that the hybridity approach merely perpetuates thinking in dichotomies and distinct entities. For the latest iteration of this critique see Hameiri and Jones, this volume.

3 Peterson, 'A Conceptual Unpacking of Hybridity', 12. 
So, although this chapter's title can be read as again reifying entities'the local/s' and 'the international/s' - the terms 'hybridisation' and 'interface', which also figure in the title, signal a relational understanding of the issues at stake. ${ }^{4}$ I shall nevertheless start by indeed talking about 'locals' and 'internationals': in the Bougainville peace process there are actors who present themselves as, and are perceived as, 'locals' and 'internationals'. These two 'camps' are highly diverse in themselves, of course, with all kinds of internal differences and frictions. But for purposes of tracing processes of peace formation it is worthwhile paying special attention to the localinternational interface. It is of particular significance, shaping the actual processes and their outcomes substantially, because the actors involved in peace formation position themselves as 'local' or 'international', and from this position define 'the other' and engage with this other when trying to 'build peace'. 5 Peacebuilding therefore is itself imbued with behaviour, actions, norms, interests that stem from this positioning. There are of course other differentiations that matter for peace formation: between male and female, rural and urban, young and old and between classes and language or other social and political groups. It is no doubt important to take these and their specific interests and agendas into account in comprehensive analyses of peace formation. Nevertheless, I think a case can be made for a particular focus on the local-international interface as I'm trying to demonstrate with this short piece on Bougainville. I will show how in Bougainville local actors affect the implementation of the internationals' predetermined peacebuilding agenda through various forms of agency, and how they appropriate international agendas and resources for their own purposes, according to their own functional logic and political economy. ${ }^{6}$

4 For different types of relational approaches in (the study of) peacebuilding see Brigg, "Relational Peacebuilding'. Brigg opts for a 'thick relationality' approach which 'reverses the prevailing priority of entity over relation in mainstream social science to focus attention on how entities continually arise or emerge through relations and processes' (61). In this chapter, I follow the more modest path of 'thin relationality', which 'draws attention to underappreciated relations among entities' and 'reaffirms the centrality of relationships of all types to peacebuilding' (66). Hunt, this volume, also builds a case for an ontology of relationships.

5 Of course, actors present themselves and are seen also along other delineating categories, for example, as 'woman' or 'Australian' or 'NGO' or 'UN'. But the identification as 'local' or 'international' is always present and effectual: a local woman, an international from Australia (or from the UN), a local (or an international) NGO.

6 Mac Ginty and Richmond, 'The Local Turn in Peace Building'; Richmond, A Post-liberal Peace; Richmond and Mitchell, Hybrid Forms of Peace. 
Local-international relations and interactions hybridise processes of peace formation. This plays out in the locale, taking the form of ongoing processes of interchange, entanglement, permeation, reassemblage and reconfiguration, which involve a host of local and international actors and institutions. ${ }^{7}$ In this understanding, the local 'becomes a verb as well as a noun or a simple descriptor of place. It is interpreted in its own right, and not as a mere adjunct to the somehow more important levels of analysis such as the state, the region or the metropolis'. ${ }^{8}$ In other words, the locale (in this case Bougainville) is conceptualised not just as another 'level' or a 'place', but a site of societal contestation-including contestation about what is and who is 'local'.

In the following, I'll present some aspects of how this plays out in the Bougainville case.

\section{Internationals and locals in Bougainville}

Peace formation on Bougainville is in its 17th year, with a critical new phase ahead, namely preparations for and conduct of a referendum on independence, most probably in 2019. In general, Bougainville is seen as a peacebuilding success story (so far), both by external observers and stakeholders directly involved in the peace process. And it is generally acknowledged that international intervention-which compared to other endeavours was a 'light intervention'-played a modest, but indispensable role. ${ }^{9}$

NewZealand supported the commencement of the peace process by offering facilitation services, providing logistical assistance, hosting the initial rounds of peace talks and negotiations, and creating a warm atmosphere for negotiators. ${ }^{10}$ With the consent of the conflict parties, neighbouring

\footnotetext{
7 Albrecht and Wiuff Moe, 'The Simultaneity of Authority'; Mac Ginty and Richmond, 'The Local Turn in Peace Building'.

8 Mac Ginty, 'Where Is the Local?', 848. In this understanding, the local is not separate from the international, and vice versa. International actors thread themselves into the local fabric, they operate from their own local positions, and their actions have to be channelled through a couple of interlinked localities; local actors and activities make their presence felt and have an impact in the international realm. The locality includes local-international relations; it is not static and territorially bound, but a dynamic and de-territorialised network. On the spatial dimension of these processes of interchange see Hameiri and Jones as well as Dinnen and Allen, this volume.

9 Regan, Light Intervention.

10 Braithwaite et al., Reconciliation and Architectures of Commitment, 46-49.
} 
states and the United Nations (UN) conducted a peacebuilding mission on Bougainville. The UN sent a small contingent, first known as the UN Political Office in Bougainville (UNPOB, August 1998 to 2004) and then as the UN Observer Mission in Bougainville (UNOMB, 2004 to June 2005). Its symbolic value, demonstrating the international community's commitment, its contribution to the weapons disposal process and its role as mediator in negotiations between conflict parties, were significant. Not least, the UN provided the external interveners with international legitimacy. ${ }^{11}$ A regional Truce Monitoring Group (TMG), which later became the Peace Monitoring Group (PMG), arrived on the island in late 1997 and stayed until June 2003. It was followed by a small, entirely civilian Bougainville Transitional Team until December 2003.

The TMG/PMG was an unarmed force of both military and civilian personnel comprising men and women from Australia, New Zealand, Fiji and Vanuatu. New Zealand led the TMG and Australia led the PMG, with Australia providing the bulk of personnel and resources. ${ }^{12}$ The TMG/PMG's mandate was to support the peace process 'through logistics, monitoring, verification, mediation and confidence building'. ${ }^{13}$

Later, after the stabilisation of the security situation on the ground, a considerable number of foreign development agencies, international nongovernment organisations (INGOs) and UN programs and institutions became active on Bougainville in support of reconstruction, rehabilitation and peacebuilding. Australia's development agency was and is the biggest of these external players. Others involved are the aid agencies of Japan, New Zealand and the United States, the European Union, the World Bank and the Asian Development Bank, as well as several UN agencies: UNDP, UNHCR, UN Women and UNICEF. Save the Children, World Vision and Oxfam are among the INGOs present. Currently it looks as if this international engagement will increase even further in the near future, with the impending referendum on independence.

11 Regan, 'The Bougainville Intervention', 202.

12 For a comprehensive account of the TMG and PMG see Adams, Peace on Bougainville; Braithwaite et al., Reconciliation and Architectures of Commitment; Breen, The Good Neighbour; Regan, Light Intervention; Wehner and Denoon, Without a Gun.

13 Australian Civil-Military Centre, Partnering for Peace, 20. 
So here you have the camp of the 'internationals'. It is self-evidently highly diverse. ${ }^{14}$ The Bougainvilleans, the 'locals', however, see these institutions and actors as outsiders, foreigners, strangers, internationals, expats-and these actors themselves know that they are seen that way, and they define themselves as such. They came in from the outside (or some of them actually operate from the outside) and they will leave and go 'home' (wherever that may be) sooner or later-or they have gone already (the PMG, the UNOMB); and others may come in, for example, for preparation and conduct of the independence referendum.

On the other hand, the internationals are not just 'outsiders', as they get more or less enmeshed in local networks. It is obvious that internationals on peacebuilding support missions can operate only by entering the locality; and by being present in the locale they become part of its social fabric. While most of the internationals stay for relatively short periods of time (months), some (a few) are around for longer (years), and this affects their status as 'internationals' or 'outsiders'. They become 'localised' to a degree, entangled in local configurations and with local actors. This affects their way of being and operating not only in the local context, but also in the context of the external entity that they come from and are part of, be it an international organisation, a sending state or an INGO.

Let's turn to the locals. Like the internationals, the locals are far from being homogenous, neatly delineated or static: among the locals are differences of power, age, gender, political affiliation, social status and so on. Some are 'local' in a pan-Bougainville context (for example, as members of the Autonomous Bougainville Government), some are 'local' in a spatially rather narrowly circumscribed context, for example, as inhabitants of a village in the mountains of central Bougainville. Connections that link the local(s) with the world beyond the locale are plenty; quite a number of locals frequently move across borders, regions and roles. Nevertheless, a significant marker of being 'local' in the Bougainville context is the

14 Disentangling 'the internationals' not only means differentiating between different types of international actors and their different approaches to, and roles in, peacebuilding (for example, the UN and its various arms and agencies, regional organisations, international financial institutions, INGOs). Nor does it only mean differentiating between intervening countries (Australia - New Zealand), or between military and civilian personnel, but also between the different layers of international institutions, from the metropolitan 'headquarters' through the 'base camp' in the country where the intervention takes place to the 'bush offices' in the field (Schlichte and Veit, 'Coupled Arenas'). Actors at these different levels engage differently with the local(s), and this impacts on, and is processed within, the international institutions with regard to understanding, conceptualising and implementing their peacebuilding mission. Available space constrains further discussion of this topic here. 
sense of belonging - to a specific place and a group of people bound by kinship ties, shared customs and culture, with a deep connection to 'land' (with 'land' being not just a material/physical reality, but imbued with cultural, spiritual and metaphysical qualities) who think of themselves as locals and are perceived as such by outsiders. 'Outsiders' can mean 'internationals' (from overseas), or people from other parts of Papua New Guinea, or people from the other side of the mountain range, depending on context.

Nonetheless, the locals cannot be conceptualised as merely local apart from the international. In Bougainville these days you can find locals who have worked for an INGO or for a UN agency for longer periods of time; they remain locals, embedded in, and loyal to, their kinship networks, while at the same time taking on the rationale and agenda of 'their' INGO or UN agency, becoming 'internationalised' and 'liberalised' to a certain extent. This affects their way of being and operating not only in their professional 'international' environment, but also in the context of the locale they come from.

But then you also have the 'local locals' as Oliver Richmond has called them, ${ }^{15}$ among them most notably customary leaders of communities and social groups, such as chiefs, elders, prophets, healers. In the dominant liberal peace discourse, these actors are either not seen at all because they do not fit into the Western liberal format of 'state', 'civil society' or 'business/economy', or they are labelled as 'traditional', implying they are 'anachronistic', 'illiberal', 'undemocratic' or 'just cultural', that is, unfit or irrelevant for peacebuilding. In fact, they play important roles in processes of peace formation and formation of political community. This is particularly so in Bougainville where 'kastom' is still strong and 'traditional' leaders — chiefs, elders—are very much in charge of dispute resolution and governance in the context of rural communities.

\section{The local/international interface}

In contrast to many other peacebuilding interventions around the globe, the extent and content of the activities of the internationals who came in to support peacebuilding could be largely controlled by the leadership of the Bougainville conflict parties. They were successful in their insistence

15 Richmond, 'A Pedagogy of Peacebuilding', 116. 
on having an unarmed intervention, despite initial concerns of the interveners, who felt uneasy about going into a volatile postconflict situation unarmed. This arrangement meant that the interveners were dependent on the locals for their security and protection. The locals developed strong feelings of responsibility for the safety of their international 'guests' (and, in fact, TMG/PMG personnel were hardly ever threatened and never attacked). ${ }^{16}$ This arrangement provided a rather robust security guarantee for the internationals. On the other hand, it affected the power relations between the internationals and the locals in the latter's favour. ${ }^{17}$

The presence of the internationals opened a secure space for former enemies to come together. The internationals played an important role in initiating conversations between the conflict parties and keeping conversations going, even in critical stages of the peace process. ${ }^{18}$ Hence it was not only the internationals' mandate in a narrow sense-to 'monitor' (TMG/PMG), to 'observe' (UNOMB) — that made their contribution to peacebuilding so valuable, but the reassurances for the locals that came with the internationals' presence, based on a plethora of activities and collateral goods that reached well beyond the formal mandate.

Actually, the 'way the intervention developed was not so much a matter of careful planning, but rather a product of complex interactions of numerous often distinct interests among both international and local actors'. ${ }^{19}$ In the following I'll try to give a glimpse of these 'complex interactions' (which were not confined to the realm of just 'interests').

The intervention set out with the conventional liberal peacebuilding agenda, but it turned out that this did not align neatly with local understandings and practices. This holds true not least regarding the conceptualisation of peace itself. One peace monitor says:

16 Regan, Light Intervention, 69. In hindsight, the Australian side concedes that 'the arrangements under which local parties would provide security to unarmed monitors worked well. An unanticipated benefit was that it also encouraged the members of the Truce and Peace Monitoring Groups to place greater importance on building good relationships with local leaders and communities so as to prevent misunderstandings that might result in threats of violence against the operation' (Australian Civil-Military Centre, Partnering for Peace, 34).

17 Regan, Light Intervention, 156.

18 Braithwaite, 'Partial Truth and Reconciliation in the Longue Durée'.

19 Regan, Light Intervention, 162-163. 
I began to realize that my understanding of 'peace' was too narrow to encompass its much more complex meaning for many Bougainvilleans. We peace monitors tended to define peace in terms of the formal truce and cease-fire agreements ... We went to villages with copies of the Burnham, Lincoln and Arawa agreements ... We poorly grasped that peace meant dealing with ... less tangible elements ... On a more complex level, which I only glimpsed, Bougainvilleans seemed committed to 'spiritual rehabilitation'. Calls for 'spiritual rehabilitation' were linked to attempts to articulate the kind of society that they wanted to build. ${ }^{20}$

The last sentence indicates how misleading liberal peacebuilding notions of 'local culture' as apolitical are, and it hints at the fundamental political significance of culture, emotion and spirituality.

The difference in understanding 'peace' played out in various dimensions of the local-international exchange, particularly in areas that are easily discredited as 'soft' and 'non-essential' by internationals. To mention just three:

First, the spiritual aspect. Another peace monitor reported: 'I experienced one healing ceremony, two crusades and a number of discussions with women who had just talked with Jesus'. ${ }^{21}$ For internationals coming from a Western secular, presumably enlightened and rational, background, it is difficult to earnestly engage with the spiritual, to actually become open to emotional and spiritual sensation and intuition and appreciate the role of myth and ritual for peacebuilding — not to speak of magic, sorcery and witchcraft. On Bougainville, however, God, the spirits of the ancestors and the unborn, the holy bushes and trees and the totem animals of the clans, who are embedded in networks that transcend the culturenature divide and the human-non-human divide, are 'actors' in their own right, with the capacity to make a difference in the visible world (which for Western internationals by and large is the only 'real' world, while for locals it is intrinsically connected to the invisible world). Accordingly, peace cannot be conceptualised without taking this non-human, invisible dimension of the world into account. The Ni-Vanuatu, the Fiji i-Taukei and the Maori in the New Zealand contingent had far fewer problems engaging with the spiritual dimensions than did the white Australians and New Zealanders.

20 Ruiz-Avila, 'Peace Monitoring in Wakunai', 98-99.

21 Parry, 'Peace Monitoring in Wakunai', 106. 
Second, 'gender issues'. A female monitor explains that the mission 'risked missing the boat with a key peace process resource - the women. We had applied our European attitudes to Bougainville and had not realized the role that women had customarily played'. ${ }^{22}$ This observation refers to the fact that most Bougainville communities are matrilineal, which translates into a rather powerful social status for women, and that women played crucial roles in the transition from war to peace in the local contexts. Engaging with the women led to significant recalibration of exchanges between interveners and locals. Given that male and female spheres are to a large extent separate in Bougainville society, male peace monitors were not capable of building the relationships that their female colleagues were able to forge.

Third, different conceptualisations of time. On Bougainville, as in other international peacebuilding interventions, the external actors tried to impose their own (tight) time frames. But at the end of the day they had to adjust to 'Melanesian time'. The Australian military commander of the PMG, for example, makes the point that 'Canberra' (that is, the Australian Government) presented the PMG with over-ambitious timetables. He says: 'But I learned that Melanesian clocks differ from other timepieces ... I quickly adapted to the Melanesian approach ... [and] although there was significant early pressure from Canberra to speed up the process, I learned that it had to progress at the pace' of the locals. ${ }^{23}$ Nevertheless, 'many in the Australian system did not really understand why the peace process moved at what, to them, seemed a frustratingly slow pace. ${ }^{24}$ On the ground, the locals disapproved with the rushed approach initially taken by PMG patrols. As a result, 'over time patrols spent longer in villages ... Patrols took the time to listen to stories, appreciating the world of villagers and creating empathy and trust'. ${ }^{25}$

The focus on process and long time frames also shaped the 'high-level' political peacebuilding process, the negotiations conducted in its course and the process of disarmament and demobilisation. This is very much in line with local customary principles and methods of peacebuilding. At the same time it poses a major challenge for the international actors, whose mindset is determined by the notion of achieving 'outcomes' and getting

22 Castell, 'Opening Doors', 121.

23 Osborn, 'Role of the Military Commander', 52-53.

24 Regan, Light Intervention, 79.

25 Breen, 'Coordinating Monitoring and Defence Support', 47. 
things done as quickly as possible. Overall, the locals largely succeeded in maintaining their pace of doing things and adjusting the international's planned timetables to local needs and customs.

These examples demonstrate that everyday processes of local-international exchange resulted in the recalibrations of relationships and involved the active renegotiation of the content and strategies of the peace intervention. In this way, the intervention was hybridised due to the agency of the locals who transformed the liberal peace agenda according to their norms, interests and ways of doing. ${ }^{26}$ It can be argued that this was an outcome of the internationals' relative weakness, and at the same time a strategy of the internationals to regain and reconfigure control and power in the international-local relationship. For example, making adjustments regarding 'gender sensitivity' can be seen as appreciation of formerly marginalised voices and as an expression of a more participatory and inclusive approach. But it also can be seen as a means to fill a gap in the intervention so as to reconfigure and expand the interveners' control and power. When presenting the success of the PMG to the outside world, the male political and military leadership of the intervention managed to bolster its image by stressing the female component, but this was originally not in the plan. In fact, it was initially met with widespread ignorance and even some resistance in the context of the military as a dominantly masculine hierarchical organisation. Only in the everyday exchange with the locals did the gender dimension emerge as a factor of major political significance.

In a similar vein, the participation of personnel from Fiji and Vanuatu (and a strong Maori component in the New Zealand contingent) can be seen as an expression of the acknowledgement of the significance of cultural context and of cultural sensitivity, but it also can be seen as a clever tactical move to increase the acceptability of the TMG/PMG to the locals. ${ }^{27}$ In an official assessment of peacebuilding interventions from 2012, an Australian Government document reads: 'Australia recognizes that its personnel rarely match the cultural skills, understanding of context and appropriateness of approach of our Pacific Island partners in regional settings'. ${ }^{28}$

26 The other side of this hybridisation is of course the transformation of local norms and ways of doing in the course of engaging with the protagonists of the liberal peace agenda. Space does not allow elaboration of this point.

27 Regan, 'The Bougainville Intervention', 193.

28 Australian Civil-Military Centre, Partnering for Peace, 43. 
Or take the aspect of religion/spirituality. Engaging with this dimension was not planned for either. However, sitting through five-hour-long church services, for example, or bringing in more padres (the so-called 'God squad'), ${ }^{29}$ changed the character of the international-local interaction. The internationals realised how useful this was for building relationships with the devout locals. It was not necessarily an indication that locals and internationals actually had a common understanding of the significance of religion and spirituality.

Or, again, the time factor. The PMG commander in the quote above speaks about the difference between 'Melanesian clocks' and 'other timepieces'. This way of talking implies a shared universal concept of time as linear and measurable. A different cultural understanding of time, however, can have profound impacts on peacebuilding, for example, if past events of linear clock time (the time of the internationals) are still 'present'. In Bougainville the spirits of the dead fighters of the war are still fighting today, because their bodies were not laid to rest according to the appropriate customary burial and reconciliation ceremonies. For many Bougainvilleans this is a major obstacle to achieving peace. There can only be peace once the bodies have been retrieved and buried according to custom. Time is not a universal given-it is something different for peacekeepers, villagers in the mountains of Bougainville, politicians in Canberra or at UN headquarters in New York. Being forced not to rush things and allow for more time to get things done is valuable in itself but might not dig deep enough.

So, even though in the course of everyday interaction with the locals the internationals' peacebuilding agenda changed, one cannot escape the impression that the internationals' engagement with local understandings of peace(building) remained within their own cultural and epistemological comfort zone, with 'the other', the local ways of being, doing and knowing (conflict, peace, culture etc.) merely seen to challenge and/or enrich liberal ways. The power of the internationals to set the paradigm within which peace is to be understood and seen as meaningful and legitimate remained unabated. On the other hand, it also has to be acknowledged that the local-international exchanges instigated self-reflection processes in the internationals' camp and led to a renegotiation of the liberal peacebuilding agenda, resulting in outcomes more conducive to the

29 Mortlock, 'A Good Thing to Do', 78. 
locals' interests, needs, norms and understanding of peace. The seemingly all-powerful liberal peace approach was re-articulated by its 'recipients' on the ground, who turned out to be not simply grateful and abiding subjects of external agendas and strategies, but powerful actors in their own right, maintaining autonomy and agency, neither merely adopting the liberal peace agenda nor resisting it totally. The result is hybrid peace formation.

The too-often misused phrase 'local ownership' has substance in the Bougainville case, with local ownership taken by the locals rather than 'granted' and 'nurtured' by the internationals. ${ }^{30}$ One aspect of the locals' agency that rarely attracts attention is that they were very smart in utilising the capacities provided by the internationals for purposes that at first sight were diverting resources from the 'real' peacebuilding tasks. For instance, transport by PMG helicopter was extensively used by chiefs and others to get them to and from meetings; villagers made comprehensive use of the PMG medical facilities or used the paper of the leaflets, flyers and newsletters distributed by the PMG for rolling their bush tobacco. So it was not only the 'core business' prescribed by the liberal peacebuilding agenda (supervise the ceasefire, assist in weapons disposal, etc.) which made the intervention useful for the locals, but also the 'collateral goods' that its presence provided-surely a distinct form of 'under the radar' local ownership. ${ }^{31}$

Of course, there were also changes on the side of the locals. Local understandings of peace, governance and legitimacy change due to the interaction with others/outsiders who have different understandings. Locals not only exploit the presence of the internationals, opportunistically adjusting to the peacebuilding and good governance talk in an instrumental manner so as to gain access to resources, but they (some, not all) genuinely change behaviours, practices and values; locals partially and selectively accepted, adopted and adapted to liberal attitudes and norms - they were more or less 'liberalised'. These processes also are expressions of the hybridisation of peace formation.

30 Krogstad, 'Local Ownership as Dependence Management'.

31 Ibid. 


\section{Conclusion}

The Bougainville case demonstrates how in the everyday localinternational exchange peace formation emerges as hybridised, with outcomes that are neither liberal nor illiberal/indigenous, but hybrid (that is, preserving elements of both the liberal and the local and at the same time transforming it into another quality). The realm of such hybrid peace formation is the locale/the locality, which is co-created and shared by a variety of interacting local and international actors and institutions, hybrid and emergent in itself. And in the context of the locale, the boundaries of 'the international' and 'the local' become porous and blurred or, as Laura McLeod puts it, 'the categorization of "local" and "international" is one with inherent slippage, and hybridity is a concept capturing this very slippage while still allowing an exploration of the interactions between local and international actors'. ${ }^{32}$

A final word on the practical political implications of all this: the encounters in Bougainville have contributed to a debate among internationals at home (in this case, in Australia and New Zealand) about the need to rethink and recalibrate one's own understandings of the international-local interface in peacebuilding. ${ }^{33}$ This has, for example, triggered reassessments of the relationship between customary and statutory law, restorative and punitive justice, or state and nonstate providers of security. Hence it can be posited that the Bougainville experience in the long run contributed to the 'turn to the local' and to the emergence of a discourse on 'relational sensibility' among international peacebuilders. This more recent interest in the local, hybridity and relationality in policy circles is evidence that there is merit in studying and talking about international-local relations in processes of peace formation also for practical political purposes. If one has the ambition to use one's research to change politics for the better, in other words, if one wants to do policy-relevant research, one has to engage with the sphere of international organisations, governments, INGOs and other political forces which are-as 'internationals'-pursuing what they call 'postconflict peacebuilding'. There can be no doubt that the findings of

32 McLeod, 'A Feminist Approach to Hybridity', 51.

33 See, for example, Australian Civil-Military Centre, Partnering for Peace, as an official document that is touched by the spirit of relational sensibility, cultural sensitivity and acknowledgement of local cultural context. For a scholarly discussion of this emerging trend see Hughes et al., Forging New Conventional Wisdom Beyond International Policing. 
such research can be used-misused, as the researcher would say-for purposes that, and by actors whom, the researcher does not agree with; this also has happened to the hybridity approach, now that it has crossed into the policy world as Oliver Richmond and Roger Mac Ginty put it in their latest piece on this topic. ${ }^{34}$ The 'hybrid turn' in the world of actual politics is open in both directions: it can potentially lead to more emancipatory peacebuilding practices beyond the liberal peace approach (as the best case), or to a refinement of counterinsurgency strategies (as the worst case) as Afghanistan, for example, shows. ${ }^{35}$

Although the latter trend gives reason for serious concern, the good news is that hybrid political orders, hybrid security governance and hybrid peace cannot be instrumentally designed, crafted or constructed. Any endeavours of internationals will always be nothing but (more or less benign or malign) elements in a complex and fluid web of relationships and interactions in a much broader mix of processes of peace formation and the emergence of political community.

34 Mac Ginty and Richmond, 'The Fallacy of Constructing Hybrid Political Orders'. We have to keep in mind, though, there is still a huge gap between the scholarly debate and political practice. Criticism of the 'local', 'hybrid' and 'relational' turns in peacebuilding as pursued mainly for instrumental or rhetorical reasons remains valid (Mac Ginty and Richmond, 'The Local Turn in Peace Building', 771). On the 'significantly different ways that hybridity can be used' see Brown, this volume.

35 Albrecht and Moe, 'The Simultaneity of Authority'; Mac Ginty and Richmond, 'The Fallacy of Constructing Hybrid Political Orders'. 
This text is taken from Hybridity on the Ground in Peacebuilding and Development: Critical Conversations, edited by Joanne Wallis, Lia Kent, Miranda Forsyth, Sinclair Dinnen and Srinjoy Bose, published 2018 by ANU Press, The Australian National University, Canberra, Australia.

doi.org/10.22459/HGPD.03.2018.07 